\title{
Article \\ Structural investigation of the Plasma Transferred Arc hardfaced glass mold after operation
}

\author{
Beata Skowrońska ${ }^{1 *(1)}$, Wojciech Sokołowski ${ }^{2}$ and Reyhaneh Rostamian ${ }^{3}$ \\ 1 Warsaw University of Technology, Poland \\ 2 Messer Eutectic Castolin, ul. Leonarda da Vinci 5, 44-109 Gliwice; wojciech.sokolowski@castolin.pl \\ 3 Isfahan University of Technology, Iran; rostamian_r@yahoo.com \\ * Correspondence: b.skowronska@wip.pw.edu.pl
}

Received: 05.01.2020; Accepted: 15.03.2020

\begin{abstract}
The paper presents the results of research aimed at detecting the causes of premature wear of molds for glass shaping, manifesting the formation of pits in the Plasma Transferred Arc pad-welds in which the working surface of the mold was shaped. The weld microstructure was tested, the chemical composition was determined in the pad-weld's cross-section, linear and surface chemical distributions were made in the pad-weld's cross-section, the surface morphology in damaged areas, and the chemical composition of surface inclusions were examined. The too high temperature of formed glass associated with wettability of the glass of the mold was indicated as the primary cause of premature mold wear.
\end{abstract}

Keywords: pad-weld; glass mold; PTA; hardfacing

\section{Introduction}

The glass industry regularly develops glass forming technology due to the need for food packaging as well as technical equipment. The growing demand for glass food packaging causes the search for new, highperformance technological solutions, both in terms of glass molding conditions and new molding tools. One of the effective methods of increasing the durability of glass metallurgical molds is the production of protective coatings by various welding and related methods, e.g. the method of arc spraying of metal coatings [1] and with the participation of intermetallic phases [2], or the method of arc welding of heat-resistant coatings [3,4] and multi-layer welds [5,6]. Protective coatings are also made by melting flame spraying [7].

Plasma surfacing [8:10] of protective coatings for glass molding tools is more and more often used. Plasma as a welding heat source has many positive features compared to other arc sources, including high melting efficiency [11], high geometrical stability of the energy stream [12], increases the wettability and adhesion of the treated solid surface [13].

Numerous considerations on the formability of glass are conducted in the literature [14], however, most of them $[15,16]$ concern the conditions of forming the shape and other properties of glass during its processing, and only a few relate to the durability of the mold or its wear resistance. The authors examined the condition of the surface of glass molds operating in conditions of too high temperature, which promotes greater efficiency of the molding process, however, leads to excessive and accelerated wear of the mold surface.

\section{Materials and research methods used}

The case of premature erosion of working surfaces of pad-welds on molds for glass forming was analyzed. The glass molds were made of aluminum bronze with an average hardness of $206 \mathrm{HB}$ and the chemical composition presented in table I. The tested pad-welds were made on the contact surfaces of the mold with glass, by plasma welding with EuTroloy 16219.42 powder from Castolin Eutectic with the chemical composition shown in table II.

Table I. Chemical composition (weight \%) of mold material

\begin{tabular}{ccccccccccc}
\hline $\mathbf{C u}$ & $\mathbf{Z n}$ & $\mathbf{A l}$ & $\mathbf{N i}$ & $\mathbf{F e}$ & $\mathbf{S i}$ & $\mathbf{P b}$ & $\mathbf{M n}$ & $\mathbf{S n}$ & $\mathbf{P}$ & $\mathbf{S b}$ \\
\hline base & 8,3 & 9,5 & 15,3 & 1,11 & 1,1 & 0,07 & 0,21 & 0,08 & 0,01 & 0,01 \\
\hline
\end{tabular}

Table II. Chemical composition (weight \%) of coating material to be deposited - powder EuTroloy 16219.42

\begin{tabular}{ccccccc}
\hline $\mathbf{N i}$ & $\mathbf{C}$ & $\mathbf{S i}$ & $\mathbf{B}$ & $\mathbf{F e}$ & $\mathbf{C r}$ & $\mathbf{A l}$ \\
\hline base & 0,3 & 3,1 & 1,0 & 2,1 & 4,9 & 0,8 \\
\hline
\end{tabular}


Structural tests were performed on the Olympus BX51M optical microscope, SEM tests on the JEOL JSM-7600F electron microscope (Peabody, MA, USA).

\section{Research results and their discussion}

The tests consisted of observation of the outer surface and microstructural tests in the cross-section of the coating-substrate. In the first stage, pitting was located in part of the pad-weld's surface and partly in the mold division plane. The location of erosive damage on the working surface is indicated by arrows in Figure 1, they are located only on the surface of the narrowing of the hole (along its entire perimeter) in the mold (a fragment of the surface remaining the longest in contact with the glass) and partly on the surface of the mold division. The intensity of the occurrence of defects was highly comparable for all examined cases, which indicates that the cause of the defect is repetitive and systematic. Leaking glass onto the mold surface indicates a dangerously low contact angle (high wettability) of the mold surface with liquid glass. In the analyzed conditions, this dangerous phenomenon may occur as a result of a decrease in surface tension at the liquid glass-gaseous environment interface (atmosphere) and at the interface between the liquid glass-mold material, due to too high glass temperature.

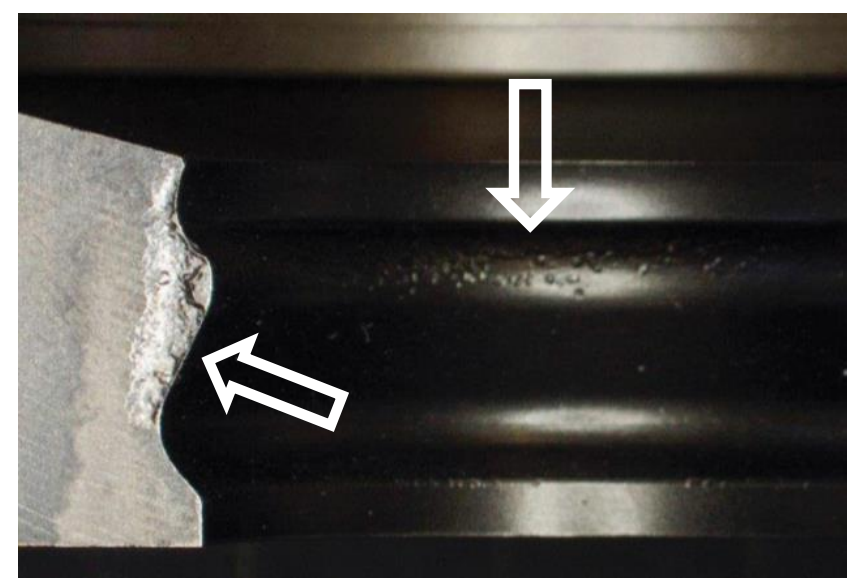

Fig. 1. Location of pits in the working part of glass molds

Tests of the pad-welds microstructure were carried out in order to check the correctness of their structure and chemical composition, on cross-sections made in the direction of the mold's radius. The preparations were collected by mechanical cutting with liquid cooling. In all cases, the sanding was performed on abrasive papers with the gradation of 100; 180; 320; 500; 800; 1000; 2000, then polished with an aqueous $\mathrm{Al}_{2} \mathrm{O}_{3}$ suspension. In order to reveal any non-metallic inclusions, the structure of the pad weldsubstrate system without etching was examined (Fig. 2). Observations on the microscope were carried out in the bright field. No non-metallic inclusions significant for the durability of the mold were observed in the obtained images, the degree of purity of the pad-weld is relatively high, characteristic for the surfacing process carried out in laboratory conditions.

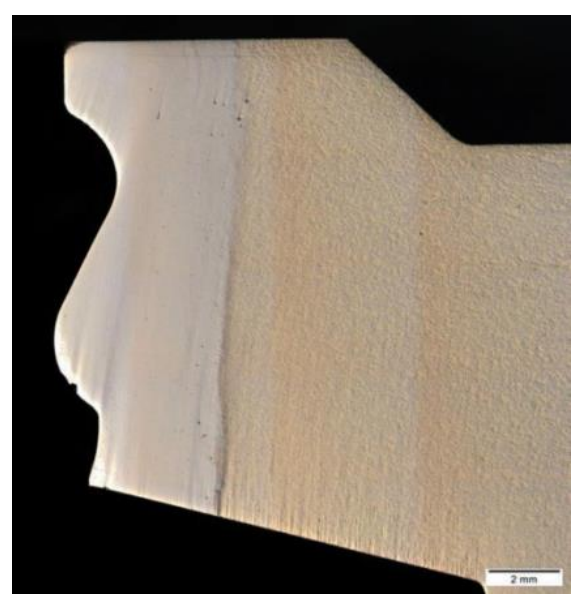

Fig. 2. Cross-section of the pad-weld along the radius of the form, image without etching 
In order to reveal the structure of the microstructural boundary of the coating penetration into the substrate (glass molds), the samples were etched with Nital (Fig. 3). Microscopic observations have shown that the coating is well bonded to the substrate, but without mixing the substrate and coating too much. The low level of mixing indicates that there is no risk of dilution of the coating material with the substrate material, which indicates that the protective potential of the coating material has been maintained at a level comparable to the nominal.

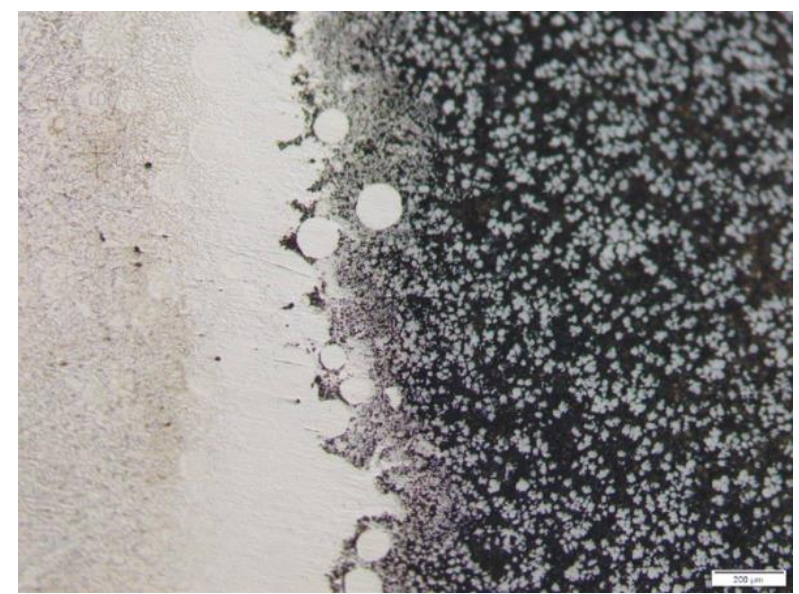

Fig. 3. Microstructure of the fusion border, pad-weld - left side, substrate - right side

Figure 4 shows the microstructure of the pad-weld in cross section, in the area of the mold's working surface and the occurrence of pits. The structure is characteristic for a plasma pad-weld. No heterogeneity or directivity of properties that could be associated with the occurrence of pitting revealed on the surface was recorded. The structure is almost cellular in nature, without a clear direction of crystallization, which means that the thermal cycle of surfacing was relatively mild. The molds were previously heated to a sufficiently high temperature to reduce the cooling rate to a safe value.

The recorded images (Figs. 4 and 5) clearly indicate that the coating's structure is not related to the pitting location. In the area of pits, no heterogeneity, segregation or other imperfections were recorded in the structure. The front of erosive destruction of the surface moved from the direction of the formed glass, and its cause was the aggressive action of oxides (the main component of the glass), which adhered too well to the surface of the mold during operation (too high wettability). In figure $4 \mathrm{~b}$, a characteristic condition was observed for the gradual extraction of single crystals from the mold's surface. Some of them are partially ripped and the grain boundaries have been damaged (grain inconsistency). No structural defects were observed in the vicinity of pits. Figure 5 shows the pad-weld's microstructure (cross-section) in the working surface area, observed on a scanning electron microscope (SEM). No structural imperfections were observed during surfacing that could be related to the occurrence of pitting. The grain size does not change in the direction of the pad-weld's thickness. The structure indicates a properly carried out surfacing process.

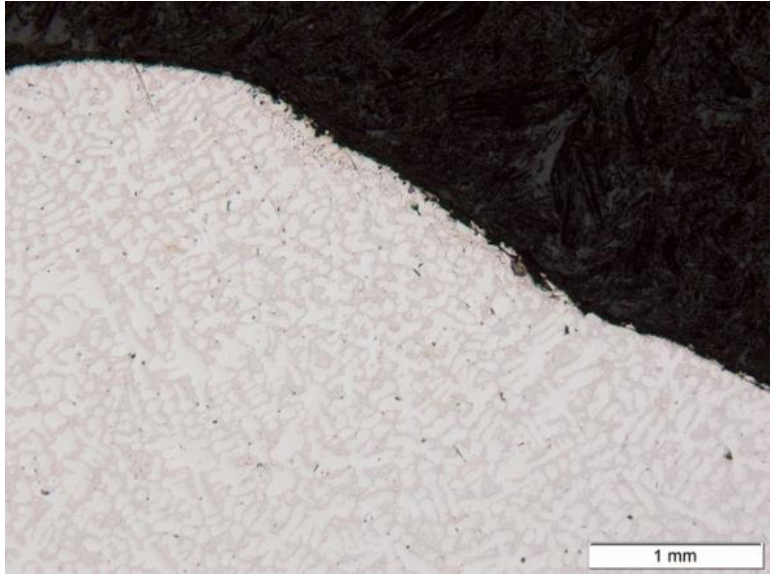

(a)

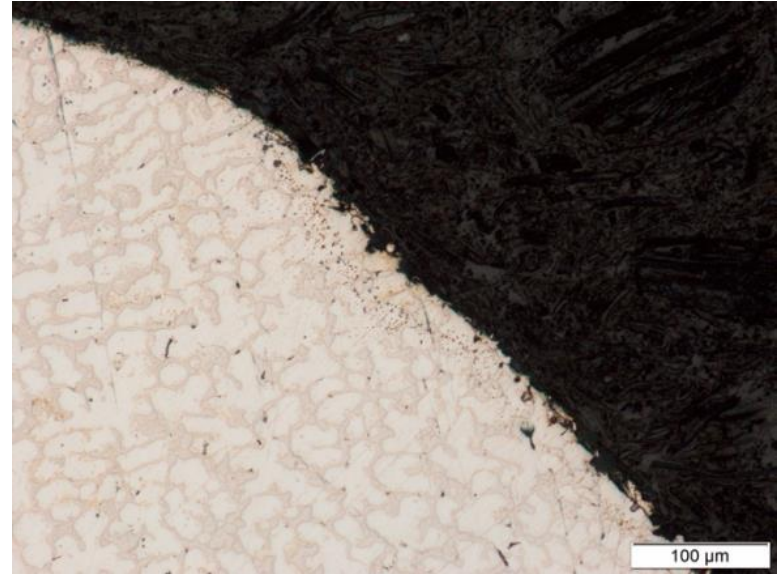

(b)

Fig. 4. Microstructure of the pad-weld in cross section at the pitting site, etched by Nital 


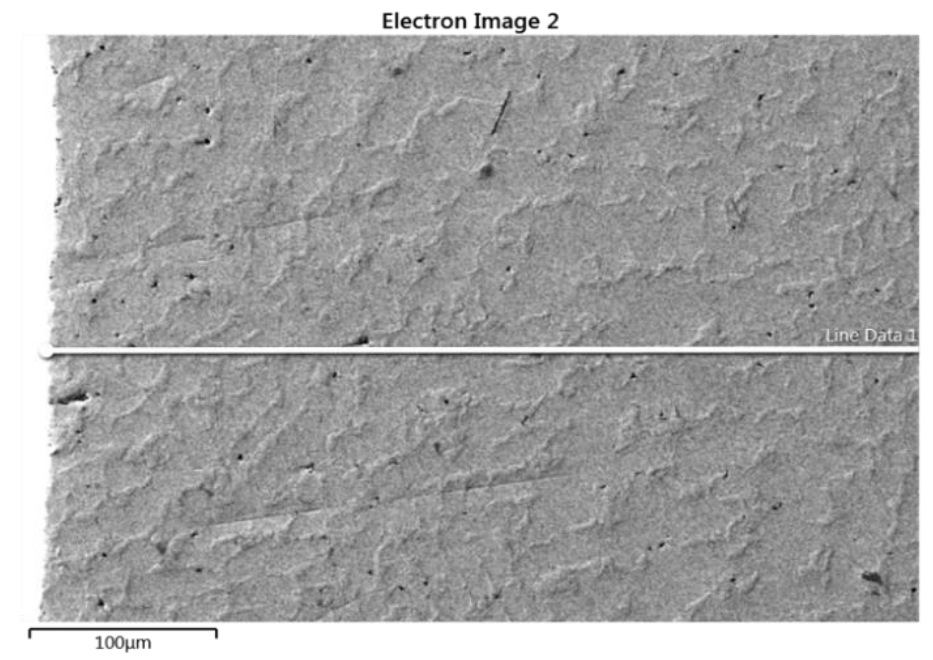

Fig. 5. The microstructure of the pad-weld in cross section near the pitting in the working surface (left side of the picture), SEM electron microscope

For the randomly selected area depicted in Figure 5, surface distributions of elements were made (Fig. 6). The distribution of iron, aluminum, copper, silicon and nickel is even. Observed chromium clusters are desirable in the structure of chromium carbides, performing the function of precipitation strengthening. In the place of occurrence in the structure of carbide precipitates, a study of the linear distribution of elements was performed (Fig. 8), the scanning line was marked in Figure 5. In the areas of precipitates, a sharp decrease in nickel concentration (Figs. 7 and 9) (the main constituent of the pad-weld's matrix) was observed, with a simultaneous increase in chromium concentration (Figs. 7 and 8). The concentration of all matrix components except the area of local carbide precipitates is even. This state indicates the homogeneity of the structure without signs of directional changes in the chemical composition. The pad-weld's material is chemically resistant to the heat cycle and high glass forming temperatures. The thermal cycle of glass pressing does not cause local depletion in elements responsible for heat resistance.

$\mathrm{Fe} K \alpha 1$

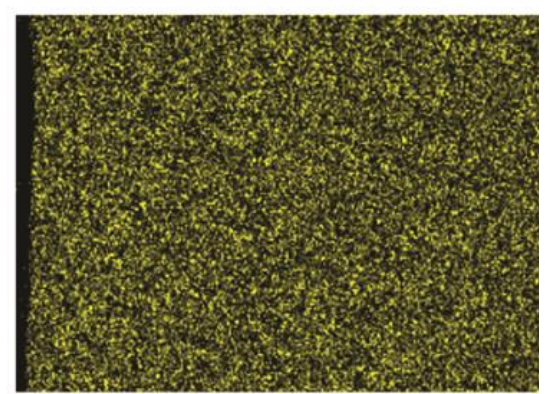

$\longdiv { 1 0 0 \mu \mathrm { m } }$

(a)

$\mathrm{Cr} \mathrm{K} \alpha 1$

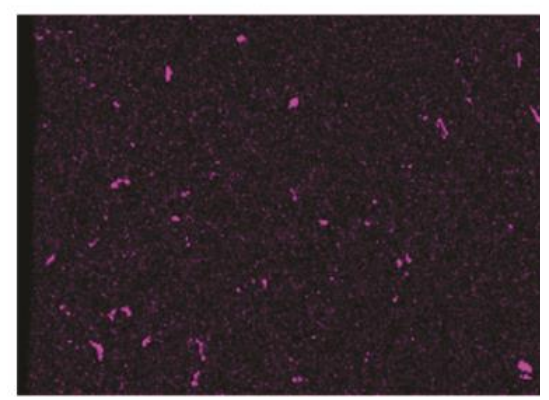

$100 \mu \mathrm{m}$
$\mathrm{Cu} K \alpha 1$

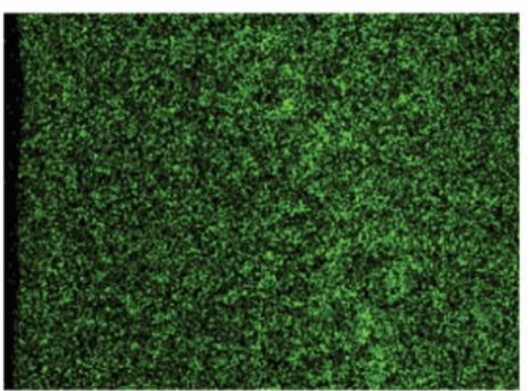

$\longdiv { 1 0 0 \mu \mathrm { m } }$

(b)

Si K 1

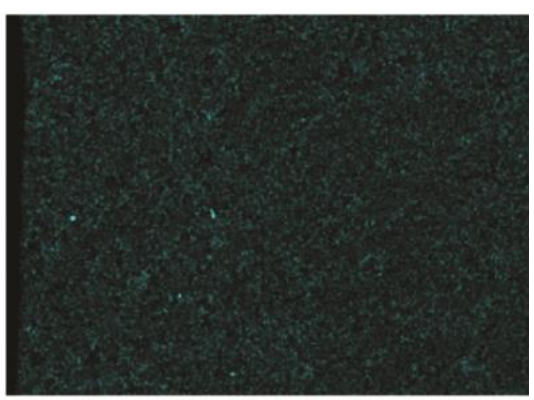

$\longdiv { 1 0 0 \mu \mathrm { m } }$

(d)

Al K $\alpha 1$

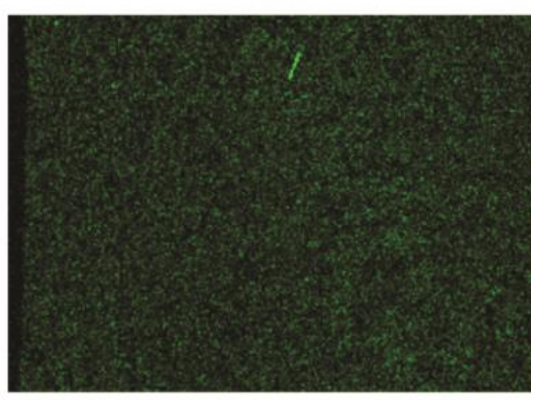

$\longdiv { 1 0 0 \mu \mathrm { m } }$

(c)

Ni $L \alpha 1,2$

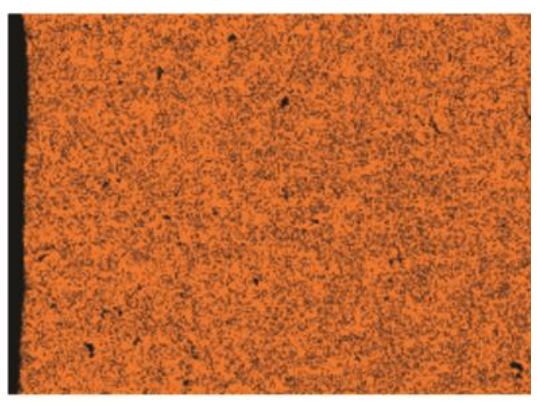

$100 \mu \mathrm{m}$

(e)

(f)

Fig. 6. Surface distribution of elements: a) $\mathrm{Fe}$; b) $\mathrm{Cu}$; c) $\mathrm{Al}$; d) $\mathrm{Cr}$; e) $\mathrm{Si}$; f) Ni, made for the area from fig. 5 


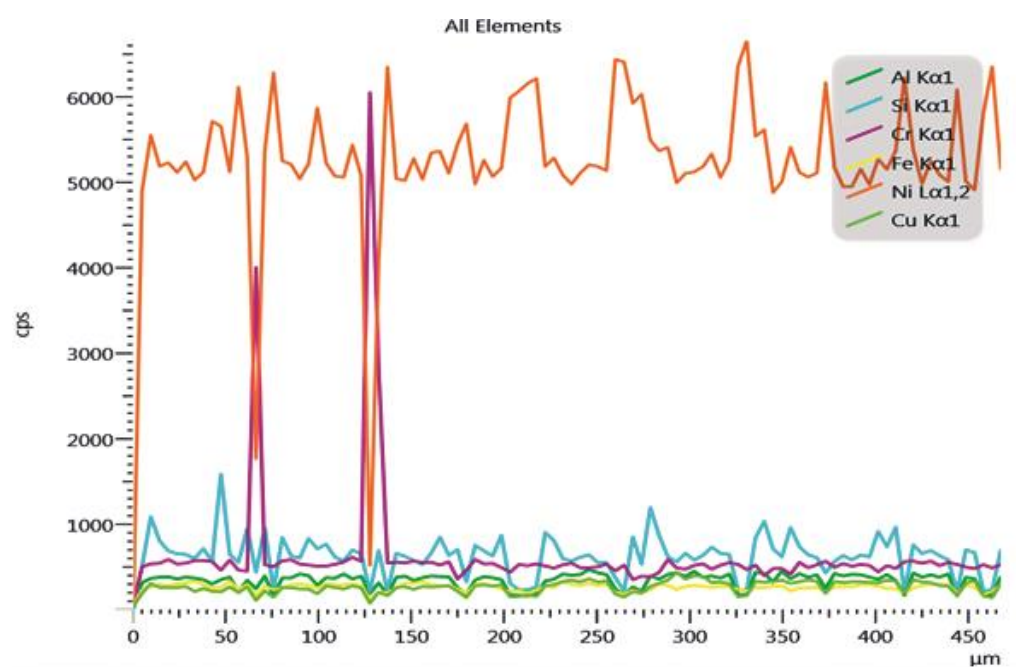

Fig. 7. Linear distributions of the elements $\mathrm{Al}, \mathrm{Si}, \mathrm{Cr}, \mathrm{Fe}, \mathrm{Ni}, \mathrm{Cu}$ in the area of precipitation

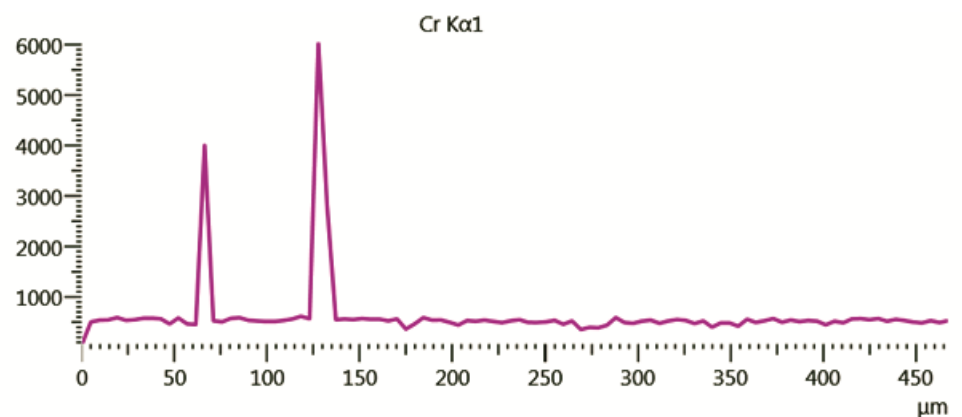

Fig. 8. Linear distribution of the $\mathrm{Cr}$ in the area of precipitation according to fig. 5

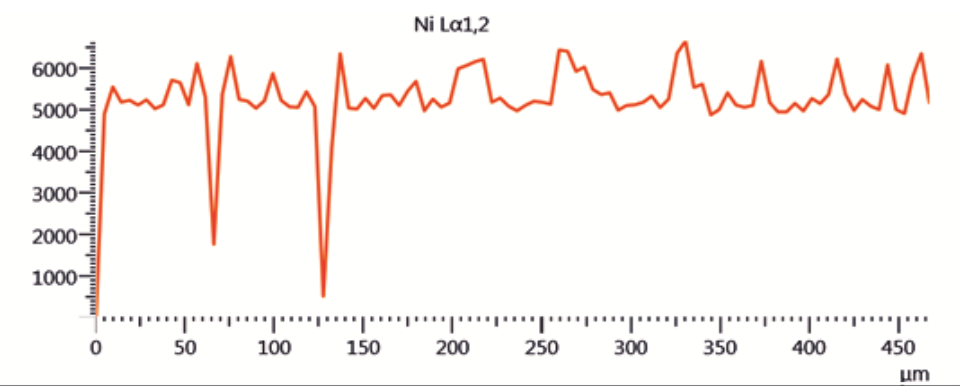

Fig. 9. Linear distribution of the $\mathrm{Ni}$ in the area of precipitation according to fig. 5

Figure 10 shows the SEM image of the pad-weld's structure with a much larger magnification compared to figure 5. The study was performed with particular regard to the area of the precipitates (marked as no. 1) and the gray phase (marked as no. 2) with morphology different from the matrix. The study of linear elemental distributions was carried out to determine the integrity of the precipitates with the matrix.

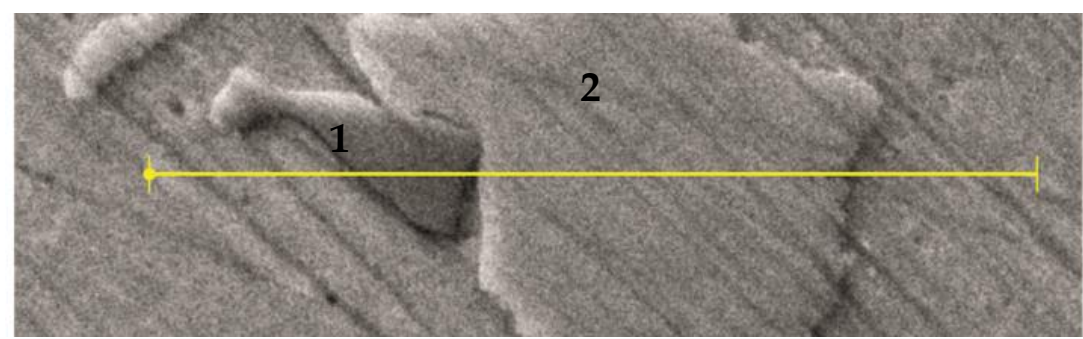

Fig. 10. Microstructure of Cr precipitation (1 gray phase) with a chemical composition scanning line

The graph in figure 11 uniquely identifies the precipitates as chromium carbides, in the place of separation an abrupt increase in the concentration of chromium and carbon was recorded. The presence of chromium carbides with a dispersion as in figures 6,7 and 10 has only a positive significance for the properties of the pad-weld, constituting the basis of the mechanism of the precipitation strengthening of the pad-weld. 


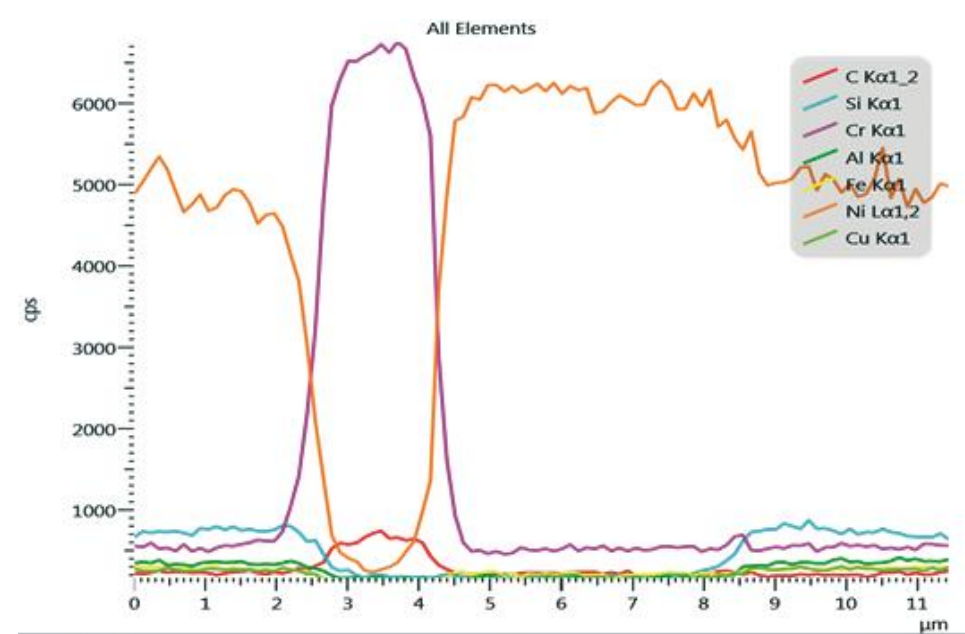

Fig. 11. Linear distribution of elements $\mathrm{Al}, \mathrm{Si}, \mathrm{Cr}, \mathrm{Fe}, \mathrm{Ni}, \mathrm{Cu}$, in the pad-weld

The linear distribution of elements from figure 11 also shows the presence of a third phase (marked 2 in figure 10) with a higher nickel content than the matrix, at the expense of other components of the alloy tested.

Figure 12 shows the results of EDS spectral analysis. Tests of the chemical composition of the pad-weld (table III) carried out in the three areas marked in figure 12a indicate uniformity of chemical composition, which clearly demonstrates the high quality of the plasma pad-weld. The chemical composition corresponds to the composition of the powder used for surfacing, taking into account the effects of remelting and partial mixing with the base material [17]. The low value of the standard deviation from the average value of the concentration by weight of individual elements confirms the homogeneity of the pad-weld's material.

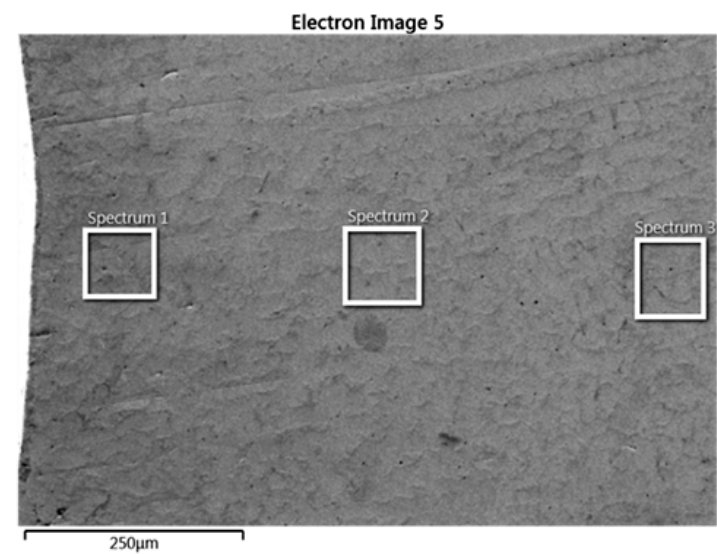

(a)

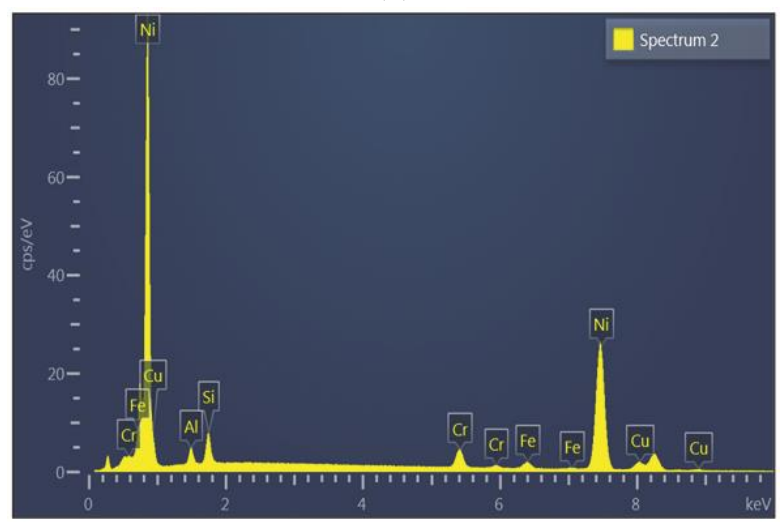

(c)

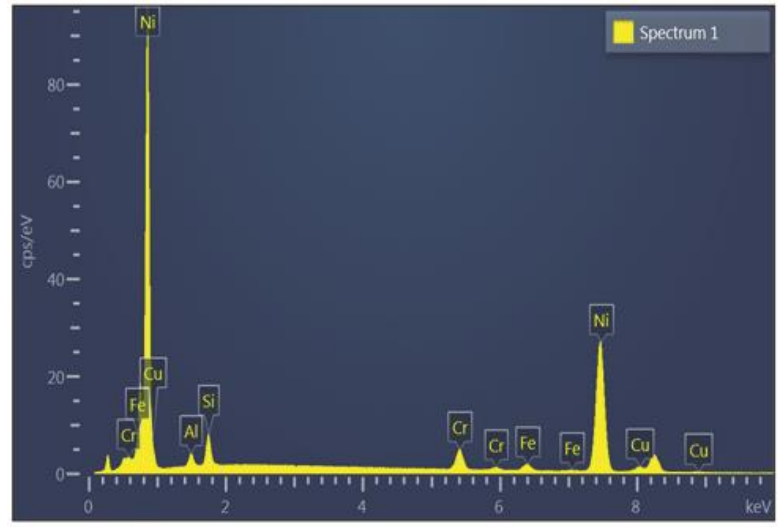

(b)

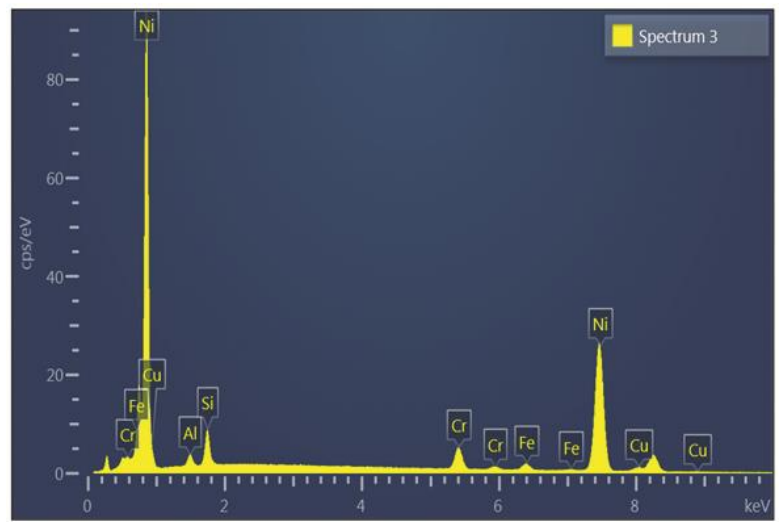

(d)

Fig. 12. EDS spectrum qualitative analysis of the chemical composition in coating: a) SEM picture in cross-section of the pad-weld, b) EDS spectrum 1 close to working surface; b) EDS spectrum 2, c) EDS spectrum 3 
Table III. Chemical composition of coating (weight \%) in selected three zones indicated on figure 11a

\begin{tabular}{|c|c|c|c|c|c|c|c|}
\hline $\begin{array}{c}\text { Spectrum } \\
\text { designation }\end{array}$ & $\begin{array}{c}\text { Spectrum } \\
1\end{array}$ & $\begin{array}{c}\text { Spectrum } \\
2\end{array}$ & $\begin{array}{c}\text { Spectrum } \\
3\end{array}$ & Max & Min & Average & $\begin{array}{l}\text { Standard } \\
\text { deviation }\end{array}$ \\
\hline $\mathrm{Al}$ & 1.38 & 1.8 & 1.21 & 1.8 & 1.21 & 1.46 & 0.3 \\
\hline $\mathrm{Si}$ & 2.90 & 2.78 & 3.24 & 3.24 & 2.78 & 2.97 & 0.24 \\
\hline $\mathrm{Cr}$ & 4.73 & 4.30 & 5.24 & 5.24 & 4.30 & 4.76 & 0.47 \\
\hline $\mathrm{Fe}$ & 2.06 & 2.03 & 2.04 & 2.06 & 2.03 & 2.04 & 0.02 \\
\hline $\mathrm{Ni}$ & 83.62 & 80.94 & 83.95 & 83.95 & 80.94 & 82.83 & 1.65 \\
\hline $\mathrm{Cu}$ & 5.31 & 8.16 & 4.31 & 8.16 & 4.31 & 5.93 & 2.0 \\
\hline
\end{tabular}

Pitting clusters located in the mold's opening (Fig. 1) are shown in figure 13, their morphology and intensity of occurrence indicates high surface sensitivity to the factor causing wear. The dimensions of the pits are in the range of a few $\mu \mathrm{m}$ to $1 \mathrm{~mm}$. Figure 13a shows a view of the surface with pits, which have a smooth geometry without clear sharp edges, and their morphology and distribution in no way correspond to the microstructure of the pad-weld. The pitting profile is gentle, indicating a gradual movement of the destruction front. At the bottom of the pits, a resident foreign body was observed, which was identified in the next stage.

Figure 14b shows the surface image recorded using a BSE (backscattered electrons) detector to obtain a material contrast image, based on which it is possible to show the qualitative phase/chemical differentiation of the sample's surface. The electron backscattering factor strongly depends on the atomic number of the tested material. Areas of fields containing nuclei of high Z elements, scatter back more electrons, thanks to which they are mapped on BSE images as brighter places (nickel matrix of the weld). In BSE images, the contrast is the result of the difference in the average value of the atomic number between individual points of the sample. Light elements identified in the surface image (Figs. 14b, 15) as dark island areas concentrated in pitting interiors are non-metallic substances. These are glass inclusions that moistened the mold's working surface. Figure 16 continued to observe (at higher image magnification values) pitting morphology and glass filling. At the border of the glass stuck on the surface of the mold and the pad-weld's material (Fig. 15), developing cracks were observed as a result of the stress state generated under the conditions of the thermal cycle at the border of substances with extremely different physical properties $[18,19]$ such as: thermal conductivity and expansion coefficient. The cracks developing on the surface in the glass-warp interface are the basic mechanism shaping the phenomenon of erosion and pitting in the working surface of the glass forming mold.

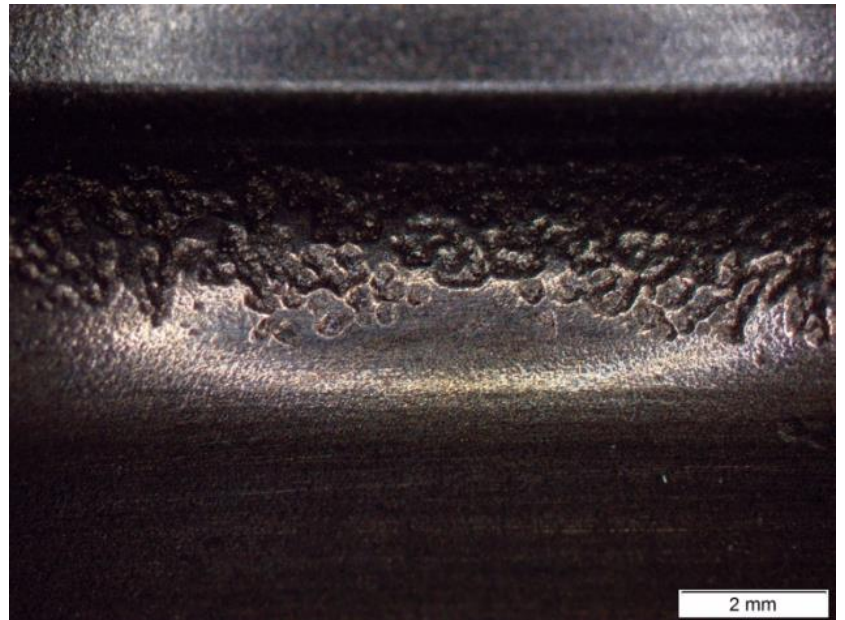

(a)

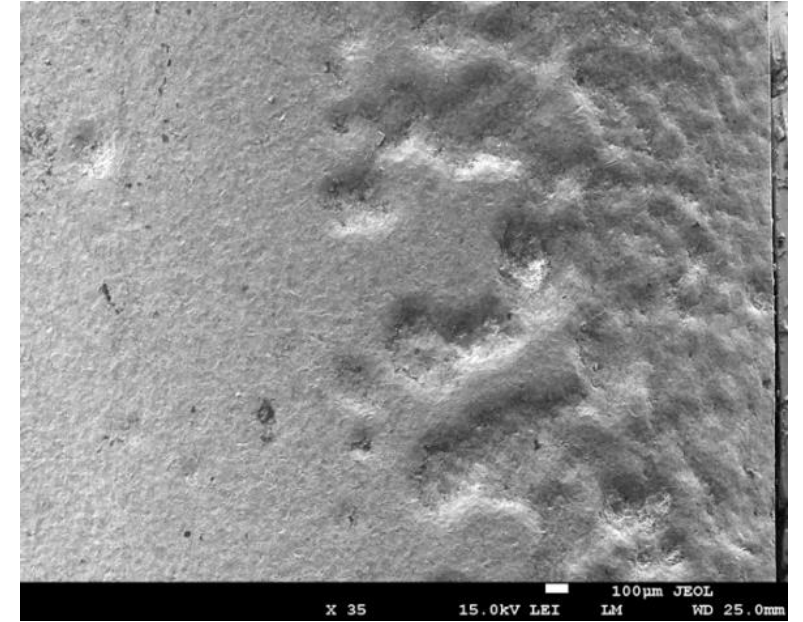

(b)

Fig. 13. Surface with pitting, a) optical microscope picture, b) SEM picture

Figure 17 shows the surface distributions of selected elements that are the basic constituents of the matrix and elements included in the glass in the area illustrated in Figure 16a. Quantitative and qualitative tests of the chemical composition within the pitting prove that the pitting bottoms are filled with glass. There is a concentration of $\mathrm{O}$ and $\mathrm{Ca}$ (basic glass components) in these areas with a simultaneous depletion of the concentration of the matrix components of the pad-weld, i.e. $\mathrm{Ni}, \mathrm{Cr}, \mathrm{Al}$ and Fe. This result indicates that the basic factor generating the mechanism for the formation and development of pits on the mold's working surface is the adhesion of glass during its formation in the metallurgical process. 


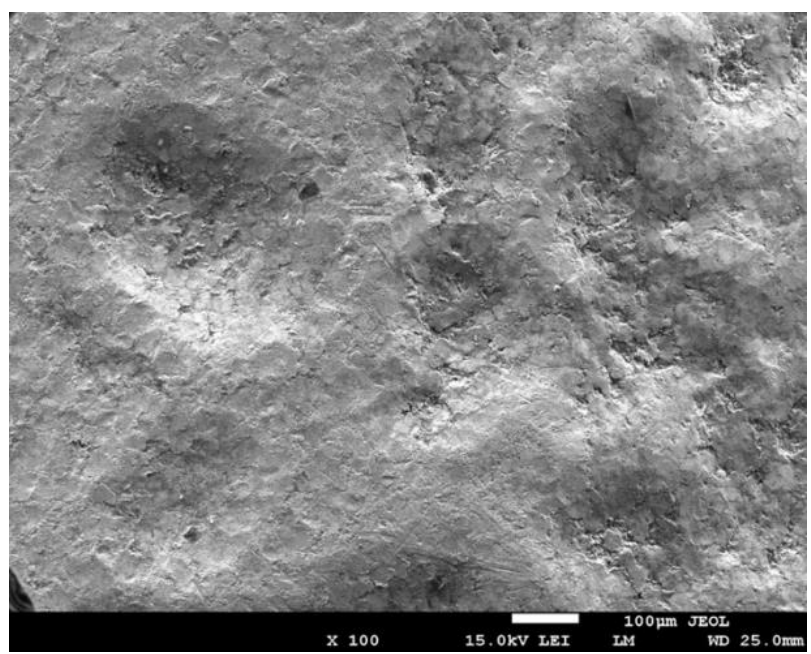

(a)

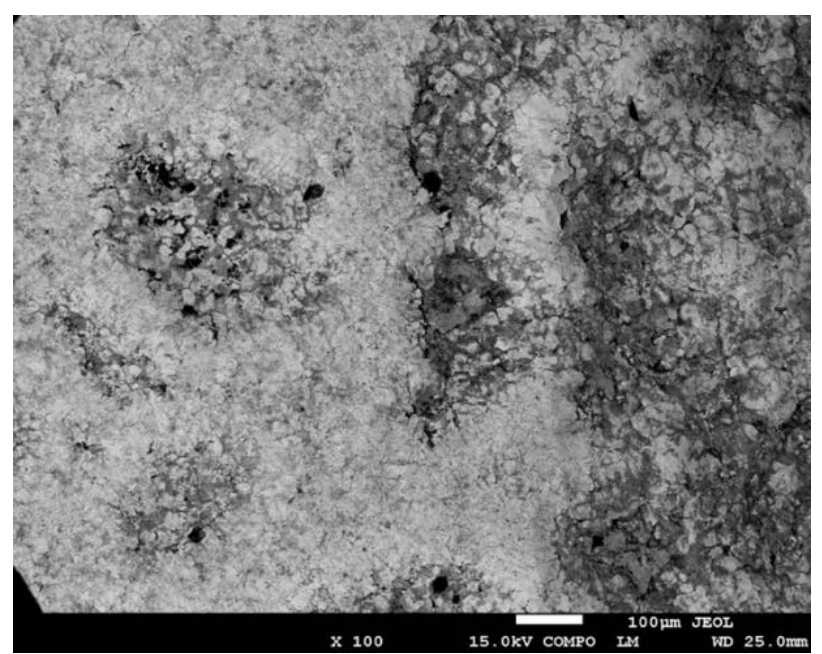

(b)

Fig. 14. Surface image with pitting, a) from the SEM electron microscope, b) from the SEM electron microscope made in material contrast using the BSE detector

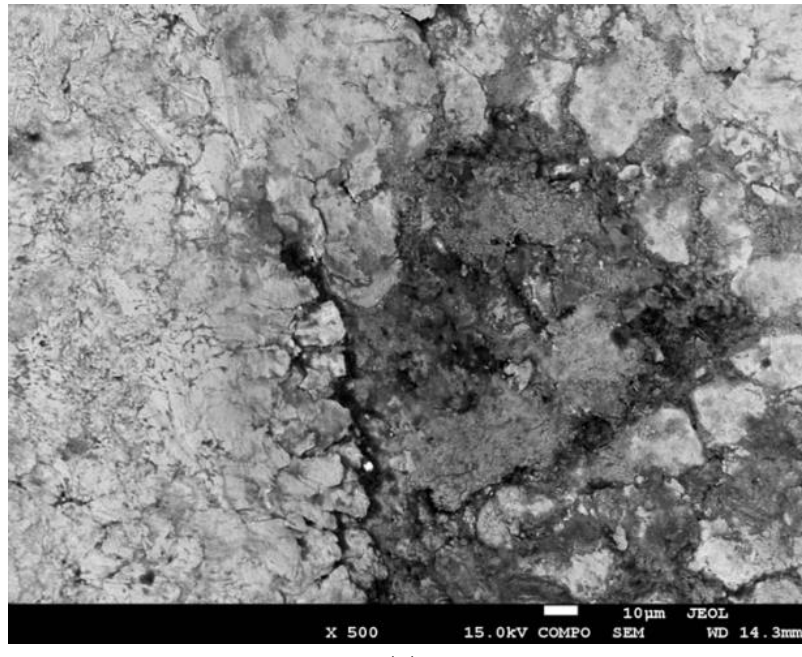

(a)

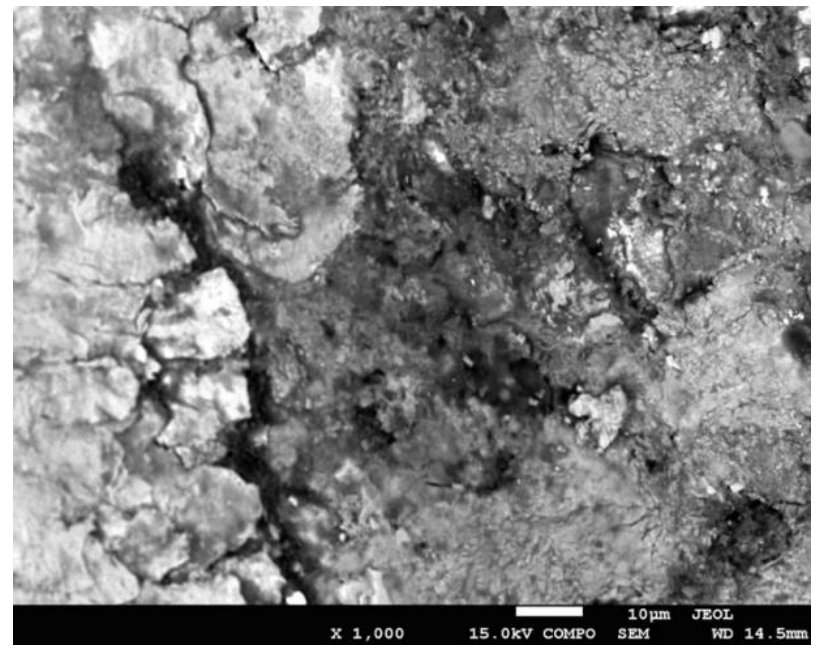

(b)

Fig. 15. SEM (BSE) image of the pitting zone

Electron Image 1

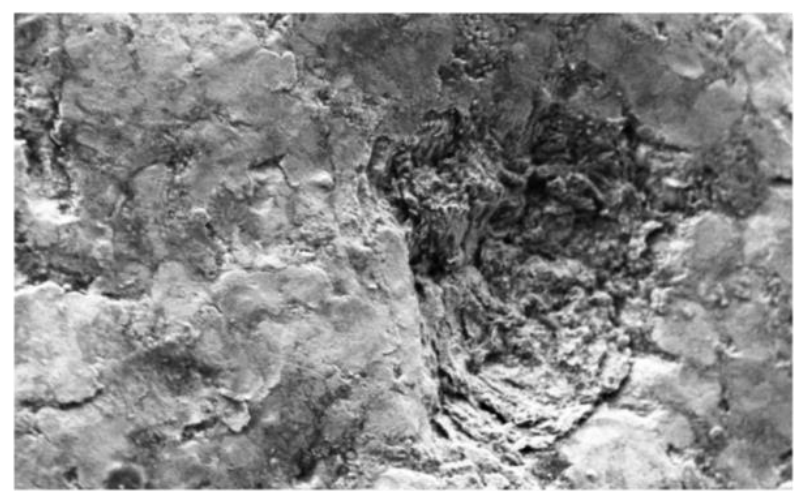

(a)

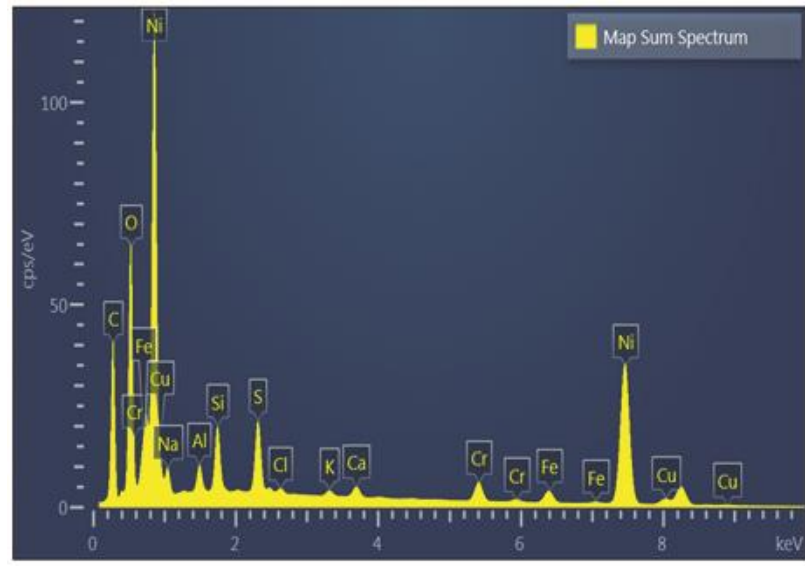

(b)

Fig. 16. a) SEM electron microscope image of the pitting surface for which EDS spectra and surface distribution of elements were taken; b) EDS spectrum for pitting area and its close surroundings 
$\mathrm{Ca} \mathrm{K} \alpha 1$

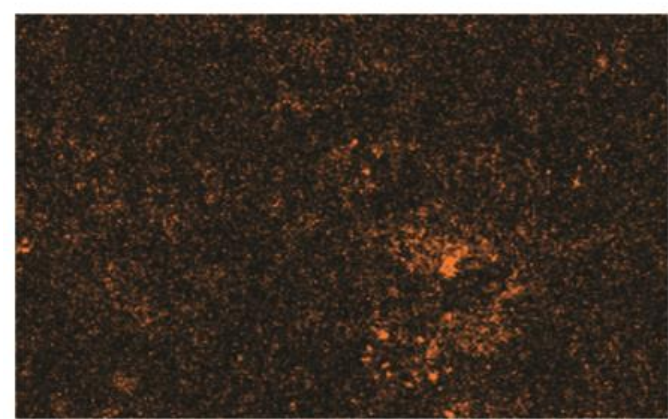

$50 \mu \mathrm{m}$

(a)

Ni $\operatorname{L} \alpha 1,2$

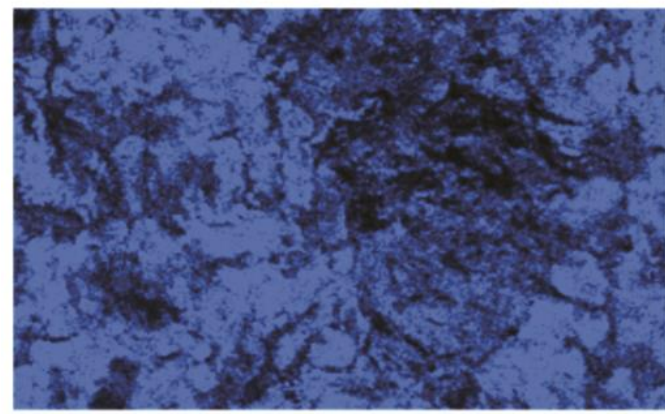

$50 \mu \mathrm{m}$

(c)

Si K $\alpha 1$

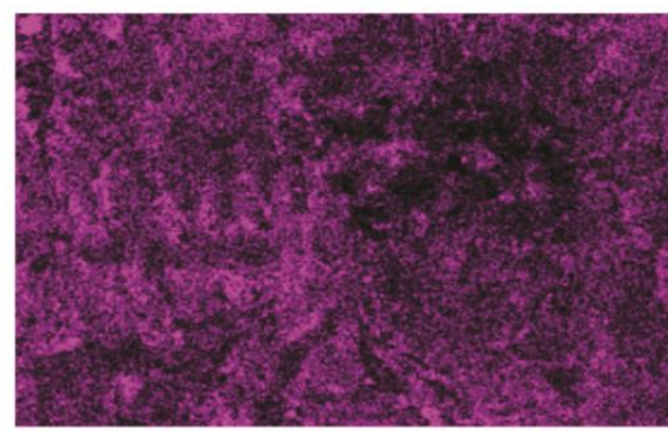

$\longdiv { 5 0 \mu \mathrm { m } }$

(e)

Fe $K \alpha 1$

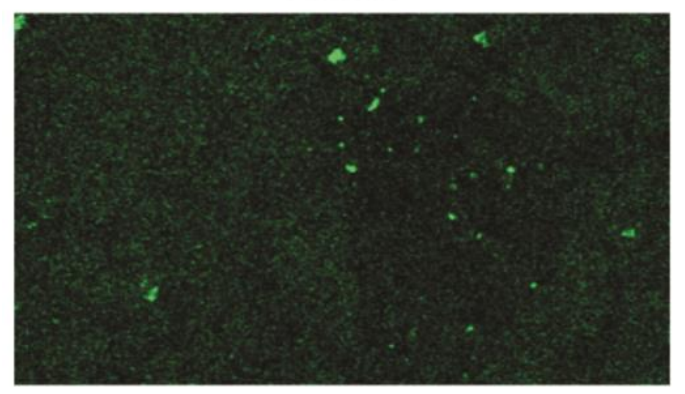

$50 \mu \mathrm{m}$
$\mathrm{O} K \alpha 1$

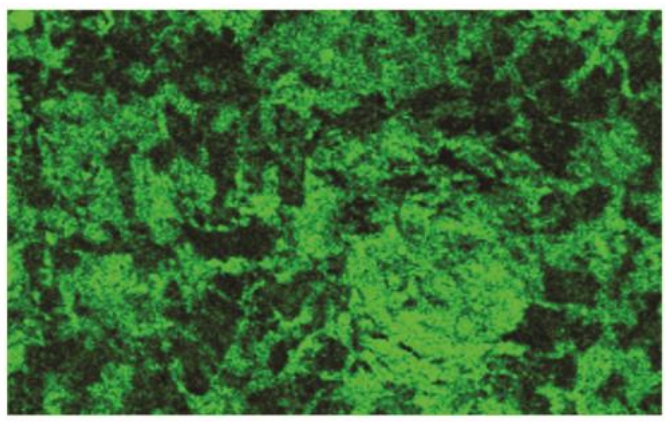

$50 \mu \mathrm{m}$

(b)

$\mathrm{C} K \alpha 1$

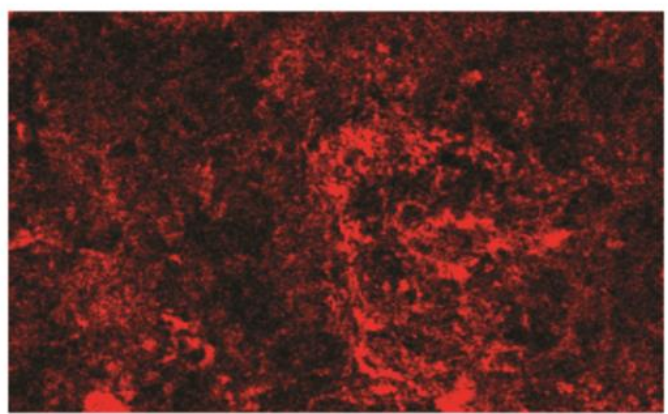

$50 \mu \mathrm{m}$

(d)

Cr K $\alpha 1$

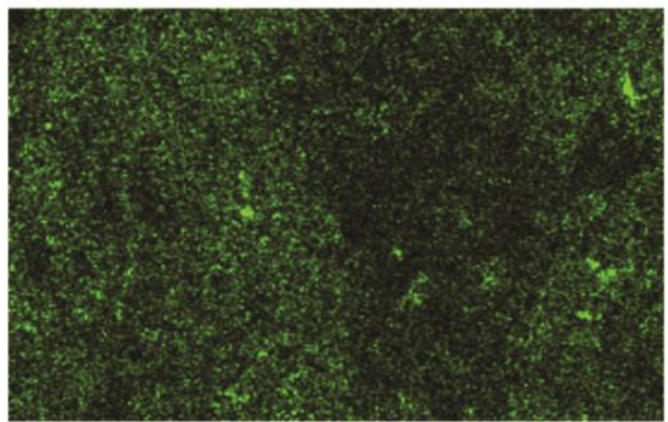

$50 \mu \mathrm{m}$

(f)

Al K $\alpha 1$

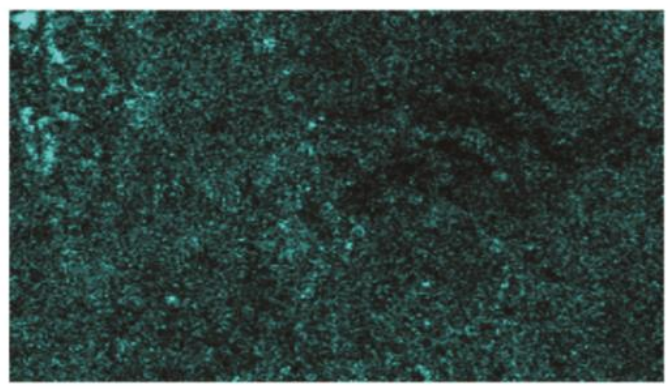

(h)

$\longdiv { 5 0 \mu \mathrm { m } }$

(g)

Fig. 18. Surface distribution of elements: a) $\mathrm{Ca}$; b) O; c) Ni; d) C; e) Si; f) Cr; g) Fe; h) Al, made for the area of pitting and it close surroundings from Fig. 14a 


\section{Summary}

The tests carried out allow for the submission of several important conclusions indicating the reasons for premature destruction of the working surface of glass molds:

1. The correct structure of the pad-weld's material was confirmed.

2. Pits described and indicated in the content of this study occurred with a characteristic and repeatable location (segregation). The intensity of the occurrence of defects is highly comparable for all examined cases, which indicates that the cause of the defect is repetitive and systematic. From a statistical point of view, damage (pits) should not be associated with potential welding defects (pad-weld defects have not been registered in the tests), whose frequency is usually random, and the location of potential defects is also most often stochastic.

Only damaged pits occur on damaged surfaces, all with similar morphology, consisting in the loss of grains torn from the working surface of the pad-weld. The nature of the occurrence of defects is closely related to technological conditions and should be associated with the physical interaction (wetting of the working surface with glass) of the mold with formed glass [20]. Due to the segregation of defects in the characteristic areas of the pad-weld, and not over its entire surface, a material factor is unlikely.

3. The bottom of all pits is filled with glass, which indicates that the glass surface of the working surface of the glass mold is too wet.

4. Too high wettability is associated with many factors driving the surface tension system at the contact point of three phases (atmosphere, liquid glass and mold surface). In the context of the case under consideration, the most important variable is the temperature of the formed glass or the surface temperature of the mold.

5. In order to reduce the wear of the working surface of the pad-weld, it is necessary to lower the glass temperature (or increase the intensity of cooling the mold) to obtain a safely low wettability with liquid glass of the mold surface during the molding process.

Author Contributions: conceptualization W.S., B.S., R.R.; methodology B.S.; validation B.S., W.S.; formal analysis W.S.; investigation B.S.; W.S.; R.R; resources W.S.; data curation B.S.; writing - original draft preparation B.S.; writing - review and editing B.S.; visualization W.S.; supervision B.S.

Funding: This research received no external funding

Conflicts of Interest: The authors declare no conflict of interest

\section{References}

[1] Klimpel A., Czupryński A., Górka J., Kik T., Melcer M., A study of modern materials for arc spraying. Welding International, 2014, Vol. 28(2), 100-6. https://doi.org/10.1080/09507116.2012.708479

[2] Chmielewski T., Siwek P., Chmielewski M., Piątkowska A., Grabias A., Golański D., Structure and selected properties of arc sprayed coatings containing in-situ fabricated Fe-Al intermetallic phases. Metals, 2018, Vol. 8(12), 1059. https://doi.org/10.3390/met8121059

[3] Gontarz G., Golański D., Chmielewski T., Properties of Fe-Al Type Intermetallic Layers Produced by AC TIG Method. Advances in Materials Sciences, 2013, Vol. 13(3), 5-16. https://doi.org/10.2478/adms-2013-0007

[4] Górka J., Kik T., Czupryński A., Foreiter W., Technology of welding hard wearing plates. Welding International, 2014, Vol. 28(10), 749-55. https://doi.org/10.1080/09507116.2012.753223

[5] Winczek J., Modeling of temperature field during multi-pass gmaw surfacing or rebuilding of steel elements taking into account the heat of the deposit metal. Applied Sciences (Switzerland), 2017, Vol. 7(1). https://doi.org/10.3390/app7010006

[6] Tomków J., Czupryński A., Fydrych D., The Abrasive Wear Resistance of Coatings Manufactured on HighStrength Low-Alloy (HSLA) Offshore Steel in Wet Welding Conditions. Coatings, 2020, Vol. 10(3), 219. https://doi.org/10.3390/coatings10030219

[7] Houdková Š., Smazalová E., Vostrák M., Schubert J., Properties of NiCrBSi coating, as sprayed and remelted by different technologies. Surface and Coatings Technology, 2014, Vol. 253, 14-26. https://doi.org/10.1016/j.surfcoat.2014.05.009

[8] Diaz V.V., Dutra J.C., D’Oliveira A.S.C.M., Hardfacing by plasma transfer arc process. Welding International, 2012, Vol. 26(2), 87-95. https://doi.org/10.1080/09507116.2010.527486

[9] Bober M., Senkara J., Comparative tests of plasma-surfaced nickel layers with chromium and titanium carbides. Welding International, 2016, Vol. 30(2), 107-11. https://doi.org/10.1080/09507116.2014.937616 
[10] Golański D., Chmielewski T., Skowrońska B., Rochalski D., Advanced Applications of Microplasma Welding. Biuletyn Instytutu Spawalnictwa, 2018, Vol. 2018(5), 53-63. https://doi.org/10.17729/ebis.2018.5/5

[11] Skowrońska B., Chmielewski T., Golański D., Szulc J., Weldability of S700MC steel welded with the hybrid plasma + MAG method. Manufacturing Review, 2020, Vol. 7(4), 15. https://doi.org/10.1051/mfreview/2020001

[12] Prasad K.S., Rao C.S., Rao D.N., Advances in Plasma Arc Welding : A Review. Journal of Mechanical Engineering and Technology Internet, 2012, Vol. 4(1), 35-59.

[13] Wolf R., Sparavigna A.C., Role of Plasma Surface Treatments on Wetting and Adhesion. Engineering, 2010, Vol. 02(06), 397-402. https://doi.org/10.4236/eng.2010.26052

[14] Lu Z.P., Liu C.T., Glass formation criterion for various glass-forming systems. Physical Review Letters, 2003 , Vol. 91(11). https://doi.org/10.1103/PhysRevLett.91.115505

[15] Suo Z.Y., Qiu K.Q., Li Q.F., You J.H., Ren Y.L., Hu Z.Q., A new parameter to evaluate the glass-forming ability of bulk metallic glasses. Materials Science and Engineering A, 2010, Vol. 528(1), 429-33. https://doi.org/10.1016/j.msea.2010.09.027

[16] Lu Z.P., Bei H., Liu C.T., Recent progress in quantifying glass-forming ability of bulk metallic glasses. Intermetallics, 2007, Vol. 15(5-6), 618-24. https://doi.org/10.1016/j.intermet.2006.10.017

[17] Lakshminarayanan A.K., Balasubramanian V., Varahamoorthy R., Babu S., Predicting the dilution of plasma transferred arc hardfacing of stellite on carbon steel using response surface methodology. Metals and Materials International, 2008, Vol. 14(6), 779-89. https://doi.org/10.3365/met.mat.2008.12.779

[18] Chmielewski T., Golański D., Selected properties of Ti coatings deposited on ceramic AlN substrates by thermal spraying. Welding International, 2013, Vol. 27(8). https://doi.org/10.1080/09507116.2011.606146

[19] Chmielewski T., Hudycz M., Krajewski A., Salaciński T., Skowrońska B., Świercz R., Structure investigation of titanium metallization coating deposited onto aln ceramics substrate by means of friction surfacing process. Coatings, 2019, Vol. 9(12). https://doi.org/10.3390/coatings9120845

[20] Wlosinski W., Chmielewski T., Plasma-hardfaced chromium protective coatings - effect of ceramic reinforcement on their wettability by glass. Adv Sci Technol Internet, 2002, Vol. 32, 253-60.

(C) 2020 by the authors. Submitted for possible open access publication under the terms and conditions of the Creative Commons Attribution (CC BY) license (http://creativecommons.org/licenses/by/4.0/). 